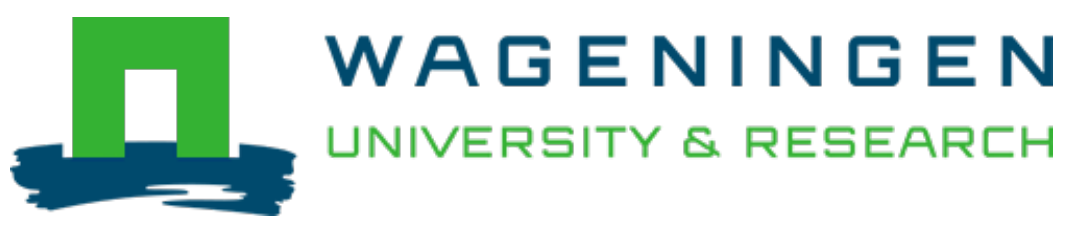

\title{
Effect of food processing of pearl millet (Pennisetum glaucum) IKMP-5 on the level of phenolics, phytate, iron and zinc
}

\author{
Journal of the Science of Food and Agriculture
}

Zanabria Eyzaguirre, R.; Nienaltowska, K.; Jong, L.E.Q.; Hasenack, B.B.E.; Nout, M.J.R.

https://doi.org/10.1002/jsfa.2527

This publication is made publicly available in the institutional repository of Wageningen University and Research, under the terms of article $25 \mathrm{fa}$ of the Dutch Copyright Act, also known as the Amendment Taverne. This has been done with explicit consent by the author.

Article 25 fa states that the author of a short scientific work funded either wholly or partially by Dutch public funds is entitled to make that work publicly available for no consideration following a reasonable period of time after the work was first published, provided that clear reference is made to the source of the first publication of the work.

This publication is distributed under The Association of Universities in the Netherlands (VSNU) 'Article $25 \mathrm{fa}$ implementation' project. In this project research outputs of researchers employed by Dutch Universities that comply with the legal requirements of Article $25 \mathrm{fa}$ of the Dutch Copyright Act are distributed online and free of cost or other barriers in institutional repositories. Research outputs are distributed six months after their first online publication in the original published version and with proper attribution to the source of the original publication.

You are permitted to download and use the publication for personal purposes. All rights remain with the author(s) and / or copyright owner(s) of this work. Any use of the publication or parts of it other than authorised under article $25 \mathrm{fa}$ of the Dutch Copyright act is prohibited. Wageningen University \& Research and the author(s) of this publication shall not be held responsible or liable for any damages resulting from your (re)use of this publication.

For questions regarding the public availability of this publication please contact openscience.library@wur.nl 


\title{
Effect of food processing of pearl millet (Pennisetum glaucum) IKMP-5 on the level of phenolics, phytate, iron and zinc
}

\author{
Romina Zanabria Eyzaguirre, Katarzyna Nienaltowska, Linda EQ de Jong, \\ Birgit BE Hasenack and MJ Robert Nout* \\ Laboratory of Food Microbiology, Wageningen University, PO Box 8291, 6700 EV Wageningen, The Netherlands
}

\begin{abstract}
Pearl millet is consumed as a staple food in semi-arid tropical regions. With a view to upgrading the micronutrient status of pearl millet-based foods, the effects of single operations and of porridge preparation scenarios on levels and in vitro solubility (IVS) of iron and zinc and mineral complexing factors (phytates: inositol phosphates and phenolic compounds) were tested. Disc milling of grain may add significant iron but this is not necessarily IVS iron. Soaking of grains results in a $25 \%$ loss of iron, but also facilitates endogenous phytate degradation, particularly when combined with milling and cooking. Germination and lactic acid fermentation both result in partial phytate degradation. Cooking does not decompose phytates, but results in complex formation of phenolic compounds as measured by a significant reduction in reactive hydroxyl groups. Because of its different distribution in the grain, zinc is generally less affected than iron. Phytate reduction by endogenous phytases is inhibited at low $\mathrm{pH}$ as caused by fermentation. Kanwa (alkaline rock salt) could be a functional cooking ingredient as a source of minerals and to react with phenolic substances. The relative IVS of iron was doubled by germination of grain and increased 3-fold by fermentation of wholemeal slurry. Zinc IVS tended to increase on cooking with kanwa, but decreased in cooked fermented flour.
\end{abstract} (C) 2006 Society of Chemical Industry

Keywords: soaking; germination; fermentation; phytase; cooking; kanwa; pearl millet

\section{INTRODUCTION}

Pearl millet (Pennisetum glaucum) is a cereal crop grown in tropical semi-arid regions of the world. ${ }^{1}$ In West African countries, e.g. Burkina Faso, it is commonly used to prepare porridges for adults and children. For example, Ben-saalga is a porridge obtained by washing and soaking whole grains of pearl millet, followed by wet milling and wet filtration. During overnight settling of the filtrate, fine flour particles form a sediment; this is cooked with a certain volume of settling supernatant to give a porridge containing about $60 \mathrm{~g} \mathrm{~kg}^{-1}$ dry matter. Our research is aimed at upgrading the nutritional value of this and similar products that form important staple foods and are produced with local resources.

In view of the importance of cereal porridges for infant feeding, the focus for improvement is on both macro- and micronutrients. Of the latter, an adequate intake of bioavailable iron and zinc is important for the prevention of developmental delays and future cognitive impairment.

Research on other cereals has shown that the digestibility of macronutrients and bioavailability of minerals are affected by factors such as the cellular anatomy of cereal products and their levels of naturally occurring complex-forming 'anti-nutritional' substances such as phytate and (poly)phenolic compounds. Phytic acid forms complexes with minerals such as $\mathrm{Zn}$ and $\mathrm{Fe}$, which lowers their bioavailability. ${ }^{2}$ In millet, several phenolic compounds can be distinguished, viz. phenolic acids, flavonoids and condensed polymeric phenols, also known as tannins. The group of polyphenolics contains a large variety of different compounds, all of which consist of one or more aromatic rings with (mostly) several hydroxyl groups attached. ${ }^{2,3}$ Tannins are polymers resulting from the condensation of flavan3-ols. The term tannins is applied to any large polyphenolic compound containing sufficient hydroxylic and other reactive, e.g. carboxylic groups, to form strong complexes with proteins and other macromolecules. ${ }^{2,4,5}$

While infant formulas, infant cereals, soy sauce and fish sauce are generally regarded as effective vehicles for food fortification, some doubt remains as to the usefulness of cereal flours and salt as fortification vehicles because of continuing technical barriers. An important technical barrier that still remains, particularly for cereal flours and salt, is finding an iron compound that is sufficiently bioavailable but which causes no adverse sensory changes to the food vehicle. ${ }^{6}$ A potential iron-containing compound is 'kanwa', i.e. alkaline salts which are used in

* Correspondence to: MJ Robert Nout, Laboratory of Food Microbiology, Wageningen University, PO Box 8291, 6700 EV Wageningen, The Netherlands E-mail: rob.nout@wur.nl

Contract/grant sponsor: European Commission; contract/grant number: ICA4-CT-2002-10047

(Received 22 August 2005; revised version received 14 October 2005; accepted 22 October 2005)

Published online 18 May 2006; DOI: 10.1002/jsfa.2527 
West and Central Africa as a tenderiser and to reduce the cooking time of beans and other tough foods. Kanwa is a naturally occurring alkaline rock salt, mainly composed of sesquicarbonates $\left(\mathrm{Na}_{2} \mathrm{CO}_{3}\right.$, $\mathrm{NaHCO}_{3} . x \mathrm{H}_{2} \mathrm{O}$ ) containing various elements such as $\mathrm{Ca}, \mathrm{Fe}, \mathrm{S}, \mathrm{Cl}, \mathrm{Si}, \mathrm{P}, \mathrm{K}$ and $\mathrm{Al}$. Alkali treatments have been shown to cause an opening and rearrangement of the phenolic ring structures and to promote oxidative polymerisation of condensed tannins. ${ }^{7}$ This may influence the bioavailability of iron and zinc. In Uganda, farmers applied this treatment effectively, detoxifying high-tannin sorghum grains, thereby improving their nutritional quality to the level of low-tannin grains.

The amount of kanwa added to foods varies with individual preferences and localities and use of as much as $100 \mathrm{~g}$ of kanwa per kilogram of cowpeas has been observed in parts of northern Nigeria. Its use in traditional food preparation might introduce some minerals into the diet. However, its nutritional and toxicological aspects have not yet been reported.

Whereas local food processors employ a variety of unit operations, little knowledge is documented on the influence of individual operations on the nutritional value of pearl millet. Recently, it was shown that soaking of whole seeds of pearl millet for $24 \mathrm{~h}$ at $30^{\circ} \mathrm{C}$ caused a loss of iron and did not much reduce the level of phytate; ${ }^{8}$ soaking of flour obtained from pearl millet resulted in leaching out of phytate but also of minerals, whereas cooking of soaked flour did not achieve degradation of phytate. ${ }^{9}$ The aim of the present investigation was to evaluate a broader spectrum of individual process operations including kanwa treatments for their effect on antinutritional factors and solubility of iron and zinc.

\section{MATERIALS AND METHODS Materials}

Pearl millet (Pennisetum glaucum) variety IKMP-5 was obtained from INERA (Institut de l'Environnement et de Recherches Agricoles, Ouagadougou, Burkina Faso). This particular variety was chosen on the basis of its relatively low phytate and tannin content and higher protein and minerals content. ${ }^{10}$

\section{Methods}

Food processing: single unit operations

Soaking in water. Soaking of whole grains in tap water $\left(1: 2 \mathrm{w} / \mathrm{v}\right.$ ratio) was carried out at $30^{\circ} \mathrm{C}$ for $24 \mathrm{~h}$. Every $8 \mathrm{~h}$ the grains were rinsed and soaking was resumed in fresh tap water to avoid anaerobic conditions. After $24 \mathrm{~h}$, the soaking was completed with a final rinsing.

Soaking in kanwa. Soaking of whole grains in kanwa solution $\left(1: 2 \mathrm{w} / \mathrm{v}\right.$ ratio) was performed at $30^{\circ} \mathrm{C}$ for $24 \mathrm{~h}$. Every $8 \mathrm{~h}$ the grains were rinsed and soaking was resumed in fresh kanwa solution to avoid anaerobic
Table 1. Composition of kanwa rocks ${ }^{a}$

\begin{tabular}{|c|c|c|c|c|c|c|}
\hline Sample & $\begin{array}{c}\text { Ash } \\
\text { (g per } \\
100 \mathrm{~g} \text { dry } \\
\text { matter) }\end{array}$ & $\begin{array}{c}\mathrm{Na} \\
\text { (g per } \\
100 \mathrm{~g} \\
\text { ash) }\end{array}$ & $\begin{array}{c}\mathrm{K} \\
\text { (g per } \\
100 \mathrm{~g} \\
\text { ash) }\end{array}$ & $\begin{array}{c}\text { Ca } \\
\text { (mg per } \\
100 \mathrm{~g} \\
\text { ash) }\end{array}$ & $\begin{array}{c}\text { Fe } \\
\text { (mg per } \\
100 \mathrm{~g} \\
\text { ash) }\end{array}$ & $\begin{array}{c}\mathrm{Zn} \\
\text { (mg per } \\
100 \mathrm{~g} \\
\text { ash) }\end{array}$ \\
\hline Kanwa 1 & 96.3 & 29.5 & 1.1 & 42 & 25 & 0.2 \\
\hline Kanwa 2 & 92.2 & 24.2 & 4.3 & 580 & 337 & 0.8 \\
\hline
\end{tabular}

conditions. After $24 \mathrm{~h}$, the soaking was completed with a final rinsing. Two types of kanwa rocks (Table 1) were obtained from the town market of Ngaoundere, Cameroon. A mixture of equal weights of types 1 and 2 was ground, suspended in distilled water in order to obtain a solution of $30 \mathrm{~g} \mathrm{dm}^{-3}$ and filtered through a Whatman No.1 filter-paper (Whatman, Maidstone, UK).

Germination. Soaked grains were spread in large Petri dishes containing a wet Whatman No. 1 filter-paper and incubated in the dark at $30^{\circ} \mathrm{C}$ for 3-4 days. The filter-paper was kept moist throughout the germination time by spraying with tap water twice per day.

Grinding. Millet grains were milled into wholemeal using a cast-steel toothed disc mill (Type LV15M, Condux-Werk, Wolfgang bei Hanau, Germany). The grinding discs are similar to the Premier disc mill that is widely used for village-scale grain milling in Africa.

Fermentation. An accelerated lactic acid fermentation $^{11}$ using the blackslopping technique was carried out at $30^{\circ} \mathrm{C}$ for $24 \mathrm{~h}$, resulting in $\mathrm{pH}$ values of 3.8-4.0.

Acidification. Samples were adjusted to $\mathrm{pH} 4.0$ using $36.5 \mathrm{~g} \mathrm{dm}^{-3} \mathrm{HCl}$.

Phytase treatment. Phytase (EC 3.1.3.8) from Aspergillus ficuum (P-9792, Sigma, St Louis, MO, USA) was suspended [2 units (U) $\mathrm{ml}^{-1}$ ] in distilled water just before use. The specific activity of the enzyme was defined by the producer as 1-5 U of enzyme liberating $1 \mu \mathrm{mol}$ of inorganic phosphorus from $29.76 \mathrm{~g} \mathrm{dm}^{-3}$ phytate per minute at $\mathrm{pH} 2.5$ and $37^{\circ} \mathrm{C}$. To condition reaction mixtures before enzyme addition, they were placed in a water-bath at $37^{\circ} \mathrm{C}$ for $5 \mathrm{~min}$, then phytase suspension was added $(1: 10 \mathrm{v} / \mathrm{v})$ and the mixtures were magnetically stirred at $37^{\circ} \mathrm{C}$ for a $2 \mathrm{~h}$ reaction period, which was terminated by placing the suspension on ice.

Cooking. Samples were cooked with continuous stirring by atmospheric boiling at $100^{\circ} \mathrm{C}$ for $5 \mathrm{~min}$, to obtain a thick porridge. Cooking was done either with tap water or with a $30 \mathrm{~g} \mathrm{dm}^{-3}$ kanwa solution (see above) at a sample dry matter:liquid ratio of 1:5 (w/v). 
Food processing: combined meal preparation processes Direct porridge with water (A). Wholemeal (see Grinding) was cooked with water (see Cooking above).

Direct porridge with Kanwa (B). Wholemeal was cooked with $30 \mathrm{~g} \mathrm{dm}^{-3}$ kanwa solution.

Overnight porridge from soaked grains (C). Grains were soaked in water (see Soaking), wet-milled (see Grinding) and cooked in water (see Cooking).

Overnight porridge from fermented wholemeal (D). Wholemeal was fermented (see Fermentation) and cooked in water.

\section{Chemical analysis}

Sample pretreatment. All samples were oven-dried overnight at $80^{\circ} \mathrm{C}$ and ground with a Pulverisette 14 mill (Fritsch, Idar-Oberstein, Germany), using a 24-knife stainless-steel rotor and a $2.00-\mathrm{mm}$ stainlesssteel screen. It was confirmed that this type of mill did not contaminate samples with $\mathrm{Fe}$ and $\mathrm{Zn}$ by comparison with non-milled millet and millet milled by crushing using a ceramic mortar and pestle. All analyses performed on the germinated grains were carried out after removal of the roots and shoots.

In vitro enzymic digestion. Mineral in vitro solubility was measured under physiological conditions in the supernatant after in vitro enzymic digestion. ${ }^{12}$ The final supernatant was mixed with an equal volume of concentrated nitric acid $\left(650 \mathrm{~g} \mathrm{dm}^{-3} \mathrm{HNO}_{3}\right)$ and filtered through a $0.45-\mu \mathrm{m}$ filter prior to determination of $\mathrm{Fe}$ and $\mathrm{Zn}$ levels.

$F e$ and $Z n$ levels. For the total level of minerals present in pearl millet, the dried and ground samples were microwave-digested and analysed by inductively coupled plasma optical emission spectrometry (ICP-OES) using an ELAN 6000 spectrometer (PerkinElmer, Wellesley, MA, USA). ${ }^{13,14}$ Soluble $\mathrm{Fe}$ and $\mathrm{Zn}$ in supernatants of enzymic digestion were measured directly, i.e. without microwave digestion.

Inositol phosphates. Phytic acid and lower inositol phosphates were determined by high-performance liquid chromatography (HPLC) using a Dionex (Sunnyvale, CA, USA) DX300, ICS2500 system with a suppressed conductivity detector range of $10 \mu \mathrm{S} .{ }^{15}$ An AS1 1 chromatographic column (Dionex) with a guard column was used. All analyses $(20-\mu \mathrm{L}$ injection volume) were carried out at room temperature. The eluents (flow-rate $1 \mathrm{~mL} \mathrm{m^{-1 }}$ ) used were as follows: $0-5 \mathrm{~min}, 0.2 \mathrm{~g} \mathrm{dm}^{-3} \mathrm{NaOH} ; 5-15 \mathrm{~min}$, linear gradient of $0.2-4 \mathrm{~g} \mathrm{dm}^{-3} \mathrm{NaOH} ; 15-20 \mathrm{~min}, 20 \mathrm{~g} \mathrm{dm}^{-3}$ $\mathrm{NaOH}$; and finally $20-35 \mathrm{~min}, 0.2 \mathrm{~g} \mathrm{dm}^{-3} \mathrm{NaOH}$. A 100-mg amount of sample (previously dried and ground) was placed in a glass tube and mixed with $10 \mathrm{~mL}$ of $18.25 \mathrm{~g} \mathrm{dm}^{-3} \mathrm{HCl}$ containing $50 \mathrm{mg} \mathrm{dm}^{-3}$ cis-aconitate (internal standard). The mixture was boiled at $100^{\circ} \mathrm{C}$ for $15 \mathrm{~min}$ in a water-bath. Next, samples were transferred into 2-mL Eppendorf tubes and centrifuged at $21000 \times g$ for $10 \mathrm{~min}$. A $0.1-\mathrm{mL}$ volume of the supernatant was homogeneously mixed with $0.1 \mathrm{~mL}$ of $18.25 \mathrm{~g} \mathrm{dm}^{-3} \mathrm{HCl}$ and $0.8 \mathrm{~mL}$ of MilliQ water (Millipore, Billerica, MA, USA) and from this mixture $200 \mu \mathrm{L}$ were analysed immediately using HPLC phials.

In addition, a standard solution was prepared containing $5.0 \mathrm{mg} \mathrm{dm}{ }^{-3} \mathrm{Na}_{2} \mathrm{SO}_{4}$ [Merck (Darmstadt, Germany) p.a.], $5.0 \mathrm{mg} \mathrm{dm}^{-3}$ sodium oxalate (O-0626, Sigma), $10.0 \mathrm{mg} \mathrm{dm}{ }^{-3} \mathrm{Na}_{2} \mathrm{HPO}_{4} \cdot \mathrm{H}_{2} \mathrm{O}$ (Merck 6346 p.a.), $10 \mathrm{mg} \mathrm{dm}^{-3}$ citric acid monohydrate (Merck K23524044 719 p.a.), $5.0 \mathrm{mg} \mathrm{dm}^{-3}$ cis-aconitate [Aldrich (Milwaukee, WI, USA) 27 1942] and $10 \mathrm{mg} \mathrm{dm}^{-3}$ myo-inositol 6-phosphate (IP6$\mathrm{Na}_{12}$ ) (Sigma P3168 lot 102K0053) in MilliQ water. cis-Aconitate solution was boiled at $100^{\circ} \mathrm{C}$ for $15 \mathrm{~min}$ before its addition to the standard solution. Furthermore, a calibration curve was obtained from standard solutions containing approximately from 0 to $400 \mu \mathrm{g} \mathrm{mL}^{-1}$ of IP6$\mathrm{Na}_{12}$. In addition, the following standards of lower inositol phosphates were used at a concentration of $50 \mu \mathrm{g} \mathrm{mL}^{-1}$ : myo-inositol 6-phosphate (IP6-Na 12 ) (Sigma P3168), myo-inositol 1,3,4,5,6pentakisphosphate $\left(\mathrm{C}_{6} \mathrm{H}_{17} \mathrm{O}_{21} \mathrm{P}_{5}\right)$ (Sigma I-9261), myo-inositol 1,3,4,6-tetrakisphosphate $\left(\mathrm{C}_{6} \mathrm{H}_{16} \mathrm{O}_{18} \mathrm{P}_{4}\right.$. $8 \mathrm{NH}_{3}$ ) (Sigma I-9386), myo-inositol 1,2,5,6-tetrakisphosphate $\left(\mathrm{C}_{6} \mathrm{H}_{16} \mathrm{O}_{18} \mathrm{P}_{4}\right)$ (Sigma I-7015) and myoinositol 3,4,5,6-tetrakisphosphate $\left(\mathrm{C}_{6} \mathrm{H}_{16} \mathrm{O}_{18} \mathrm{P}_{4}\right)$ (Sigma I-7896). myo-Inositol 1,3,4,5-tetrakisphosphate $\left(\mathrm{C}_{6} \mathrm{H}_{16} \mathrm{O}_{18} \mathrm{P}_{4} .8 \mathrm{NH}_{3}\right)$ (Sigma I-8636) and myoinositol 1,4,5-triphosphate $\left(\mathrm{C}_{6} \mathrm{H}_{15} \mathrm{O}_{15} \mathrm{P}_{3}\right)$ (Sigma I7012) were used at a concentration of $100 \mu \mathrm{g} \mathrm{ml}^{-1}$.

Phenolic substances. Phenolic compounds (PC) were extracted from $100 \mathrm{mg}$ of millet flour by adding $1.5 \mathrm{~mL}$ of $1: 100 \mathrm{v} / \mathrm{v} \mathrm{HCl}$ in methanol, followed by continuous stirring at $25^{\circ} \mathrm{C}$ for $20 \mathrm{~min}$. The suspension was then centrifuged at $18000 \times g$ for $10 \mathrm{~min}$ and $1 \mathrm{~mL}$ of the supernatant was collected. Next, the pellet was re-extracted with $1 \mathrm{~mL}$ of $\mathrm{HCl}-$ methanol as described above and $1 \mathrm{~mL}$ of the supernatant was pooled with the previously obtained supernatant. A Folin-Ciocalteu assay was used to determine the level of polyphenolic compounds (reactive hydroxyl groups) in pearl millet. ${ }^{16}$ Gallic acid was used as a standard in this assay and the results were expressed as mg gallic acid per $100 \mathrm{~g} \mathrm{DM}$ and converted to $\mathrm{OH}$ equivalents (1 $\mathrm{OH}$ eq $\left.=170 \mathrm{mg} \mathrm{OH} \mathrm{kg}^{-1} \mathrm{DM}\right)$. The level of tannins in the millet samples was determined with the acid butanol ${ }^{16,17}$ and the vanillin methods. ${ }^{18,19}$

\section{Statistics}

All experiments were performed in duplicate, with duplicate measurements. Data are reported as mean values with standard deviations. The data were analysed using the statistical program SPSS 11.0 
(SPSS, Chicago, IL, USA) and the one-way analysis of variance (ANOVA) model was used applying the least significant difference (LSD) test to evaluate significant differences among means.

\section{RESULTS AND DISCUSSION Kanwa}

As can be expected from a natural material, the composition of kanwa can vary, as indicated by the analysis as shown in Table 1. All the same, it can be concluded that kanwa mainly contributes $\mathrm{Na}$ and $\mathrm{K}$, while the levels of $\mathrm{Fe}$ and $\mathrm{Zn}$ are rather low.

\section{Polyphenols as hydroxyl equivalents}

Millets contain a variety of phenolic substances, carrying different numbers of reactive hydroxyl groups. For instance, tannic acid contains 25 hydroxyl groups per molecule, compared with three for gallic acid, which is widely used as a calibration standard in chemical analyses. Owing to processing, the distribution and composition of phenolics might be subject to change. It was therefore decided to look for a common denominator, namely reactive hydroxyl groups. The response of the Folin-Ciocalteu method was tested as a function of molar hydroxyl equivalents represented in the standard gallic acid, in comparison with ferulic acid, vanillic acid, catechin, caffeic acid and tannic acid. The results in Fig. 1 show that within a bandwidth, the various compounds tested responded with the same order of magnitude when normalised for their number of hydroxyl groups. The data obtained in these experiments were calculated against gallic acid as prescribed by procedure; Fig. 1 shows, however, that this method gives a representative view of the number of reactive hydroxyl groups irrespective of the (poly)phenolic compound from which they originate.

The acid butanol assay reacts with all units containing hydroxyl groups except the terminal unit and the vanillin method reacts with the terminal units or flavan-3-ol only. By comparing the absorbances obtained from the two assays, it is possible to determine the relative degree of polymerisation. ${ }^{17}$ Two different acid-butanol assays were used, in which proanthocyanidins (flavan-3-ols) are converted into anthocyanidins and determined spectrophotometrically. The assays were carried

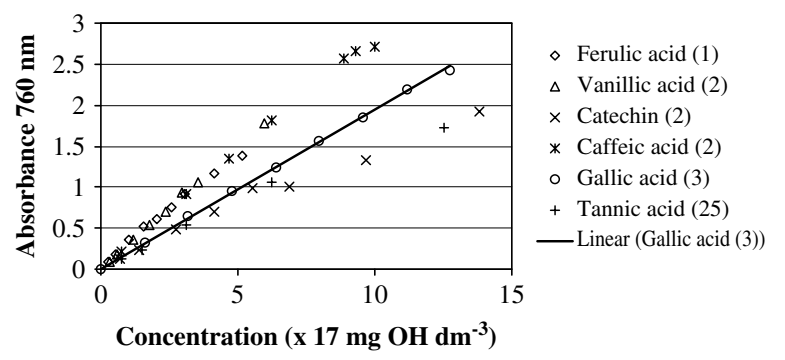

Figure 1. Reaction of phenolic substances containing single or multiple reactive phenolic hydroxyl groups (number of $\mathrm{OH}$ per molecule in parentheses), using the Folin-Ciocalteu assay. out according to Melake-Berhan et al. ${ }^{18}$ and to Hagerman. ${ }^{17}$ The main difference is the addition of $20 \mathrm{~g} \mathrm{dm}^{-3}$ ferric ammonium sulfate reagent in the latter assay. The iron is added because it enhances the colour reaction. It is known that the metal ion catalyses the formation of free radicals, which in this assay will result in an increase in absorbance. Even small amounts of iron, copper or manganese enhanced the yield of anthocyanidins. ${ }^{19}$

The vanillin assay is a quantitative measurement of condensed tannins. It is specific for a narrow range of flavanols and dihydrochalcones, which have a single bond at the 2,3-position and free metaoriented hydroxyl groups on the B-ring. ${ }^{7,20,21}$ One major problem with the vanillin assay is that the reactions of the standard and tannin follow different kinetics, making it difficult to use catechin as a valid standard for determining tannin. It is known that changing the reaction solvent can dramatically change the rates of the reaction and the modified vanillin assay takes advantage of this effect of solvent on kinetics. When glacial acetic acid is used as a solvent instead of methanol, tannin (proanthocyanidins) and catechin will react with similar kinetics. Only the terminal units of the tannin react with vanillin in glacial acetic acid. ${ }^{17}$

The levels of tannins as determined using the acid-butanol and the vanillin assays were very low (approximately 1000-fold less; data not shown) and insignificant compared with medium-tannin sorghum used for comparison.

\section{Individual unit operations}

Table 2 presents the effects of single unit operations on either whole grains or on wholemeal, affecting the levels of minerals and also phytates and phenolics. As earlier research showed that IP6 (inositol hexakisphosphate) and IP5 (inositol pentakisphosphate), but not IP4 (inositol tetrakisphosphate), reduce mineral bioavailability, ${ }^{22}$ the levels of IP5 + IP6 were presented as a total.

From whole grains, soaking in tapwater leaches out some iron; as the absolute level of in vitro soluble (IVS) iron remained similar, this slightly improved the iron solubility expressed as fraction of total iron, whereas zinc is not significantly affected. Soaking causes a significant $(P<0.05)$ degradation of phytates, with formation of IP5 and several configurations of IP4 (compare Fig. 2 traces I and II); it also results in an increase of reactive hydroxyl groups, resulting from either enzymatic degradation of complexes or from depolymerisation of polyphenolics. Germination after soaking enhances these effects, leading to a marked increase in IVS iron. Soaking in kanwa increased total iron but not its solubility. Phytate was degraded to a similar extent as in tap water, whereas phenolics were not affected. Apparently, antinutritional factors are not affected by kanwa.

Grinding grains to wholemeal using a cast steel disc mill had a tremendous effect on the total iron level, 


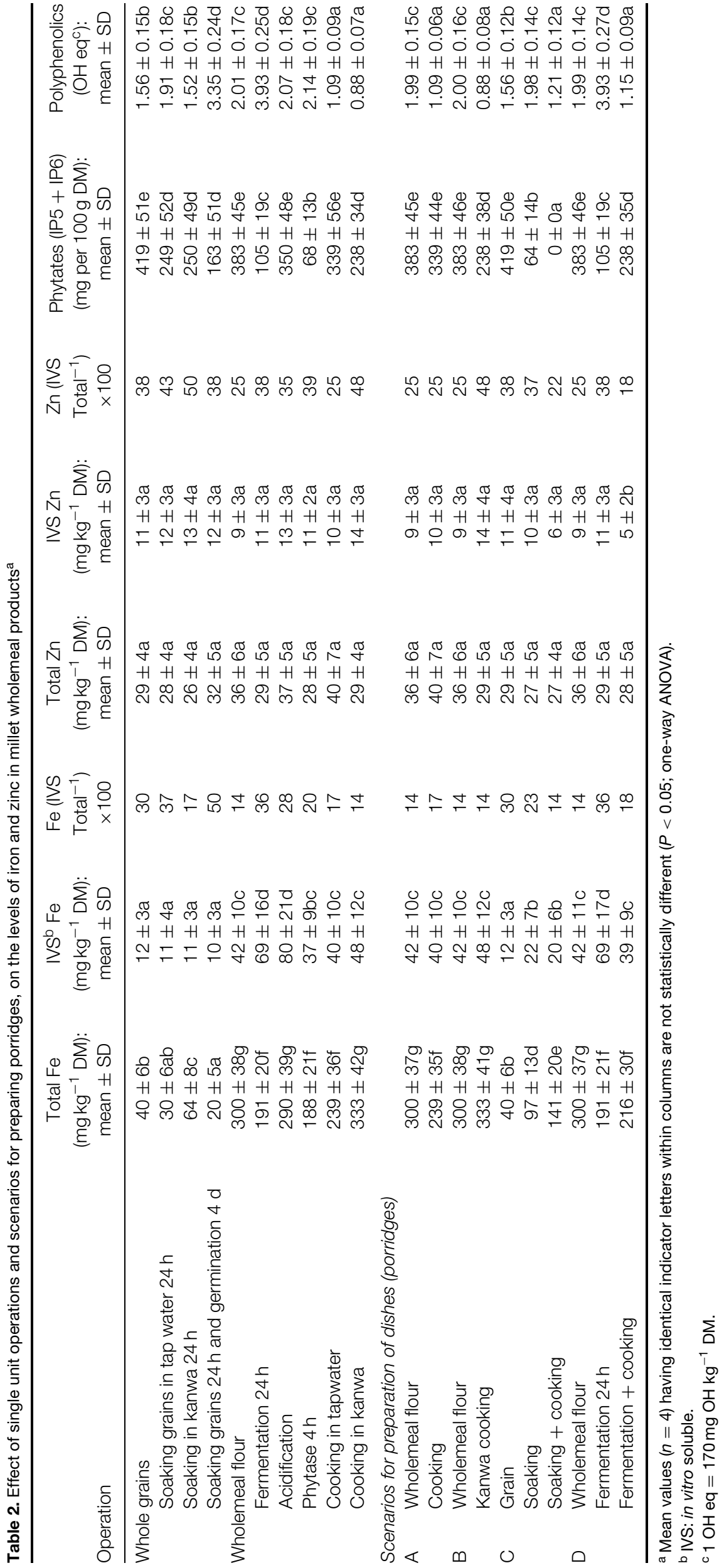



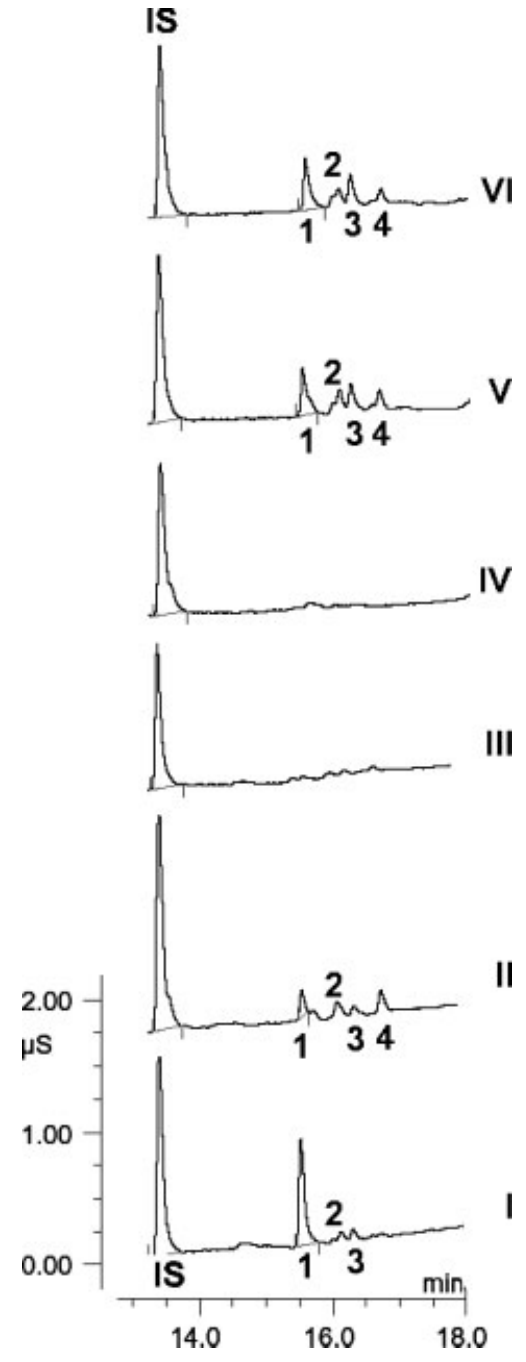

Figure 2. Effect of bioprocessing on inositol phosphates in pearl millet. Treatments: I, whole unprocessed grain; II, whole grain, soaked in tapwater for $24 \mathrm{~h}$ at $30^{\circ} \mathrm{C}$; III, same as II, followed by wet milling and cooking into porridge; IV, wholemeal suspended in tapwater, incubated with phytase for $2 \mathrm{~h}$ at $37^{\circ} \mathrm{C}$; $\mathrm{V}$, wholemeal suspended in tapwater, fermented using accelerated lactic acid fermentation for $24 \mathrm{~h}$ at $30^{\circ} \mathrm{C}$; VI, wholemeal suspended in tapwater, acidified with $\mathrm{HCl}$ to $\mathrm{pH} 4.0$ and incubated for $2 \mathrm{~h}$. Peaks: IS, cis-aconitate internal standard; 1, IP6 (phytate: myo-inositol hexakisphosphate); 2, IP5 (myo-inositol pentakisphosphate); 3, IP4 (configuration 1,2,5,6-); 4, IP4 (configurations 1,3,4,6-, 3,4,5,6- and 1,3,4,5-).

whereas zinc remained unaffected. As a result, levels of IVS iron were generally much higher than in soaked whole grain. Nevertheless, most of the added iron was insoluble. With an aqueous suspension of wholemeal as a starting point, lactic acid fermentation and acidification increase IVS iron. The acidification treatment was included to distinguish other impacts of lactic fermentation (e.g. of microbial enzymes) from merely the lowering of $\mathrm{pH}$. Whereas fermentation and acidification treatments both degrade phytate incompletely (cf. Fig. 2, traces V and VI, respectively), fungal phytase strongly degrades phytate (Fig. 2, trace IV). Whereas fermentation affected phenolics significantly $(P<0.05)$, acidification had no significant effect; nevertheless, the IVS iron is increased by both fermentation and acidification. This suggests that acidity is a prime factor determining iron solubility. The levels of zinc are not influenced in a significant way (Table 2). Cooking, either in water or in kanwa, has no important effects on iron, zinc and phytate. In contrast, reactive hydroxyl groups are significantly decreased, presumably because they react to form complexes with, e.g., proteins, starch and possibly some minerals.

Germination of grain, followed by fermentation of wholemeal and soaking of grain, gave the highest level of IVS iron. As recommended by Hurrell et al., ${ }^{6}$ the molar ratio of phytate to iron should be decreased to $<1: 1$ and ideally to $<0.4: 1$ to achieve adequate iron bioavailability. A molar ratio of $<1: 1$ was achieved by the treatments fermentation $(24 \mathrm{~h}, 0.47: 1)$, phytase (4h, $0.31: 1)$ and cooking in kanwa $(0.60: 1)$.

The total levels of zinc varied much less than those of iron, presumably because zinc is more evenly distributed in the endosperm as opposed to iron, which is mostly present in the testa. As for the molar ratio of phytate to zinc, values of $<12.5: 1$ have been recommended, preferably $<10: 1 .^{23} \mathrm{~A}$ ratio lower than 10:1 was achieved by soaking in water $(8.86: 1)$, soaking and germination $(5.08: 1)$, fermentation $(24 \mathrm{~h}$, 3.55:1), phytase $(4 \mathrm{~h}, 2.40: 1)$, cooking $(8.44: 1)$ and cooking in kanwa $(8.21: 1)$.

\section{Combined meal preparation processes}

As shown in Table 2, the total levels of iron showed a large increase in porridge $\mathrm{C}$, for which millet grains were soaked overnight and cooked into porridge. This increase is difficult to explain; possibly endogenous enzymes converted minerals into a more readily analysable form. Alternatively, dry matter losses from soaking, may have led to apparent mineral increments. Other meal preparations led to moderate losses, due to leaching of water-soluble iron components, except for cooking in kanwa, which added a little iron.

In absolute terms, the highest yield of IVS iron was obtained after cooking in kanwa, owing to its rich mineral composition. Grains had a lower level of IVS iron than wholemeal, owing to the milling effect.

Fermentation and cooking in water resulted in an increase in the percentage of IVS iron. Overall, cooking tended to decrease IVS iron. Presumably, this reduction was caused by the fact that phytate was present in considerable quantity - except in porridge $\mathrm{C}$ - and complexes could be formed with the iron present in the product. In addition, cooking always gave a reduction in IVS iron because of complexation between iron and reactive hydroxyl groups. Even in the absence of phytate (porridge $\mathrm{C}$ ), there was a reduction in the level of IVS iron due to the hydroxyl reaction. Regarding the molar ratios of phytate to iron, products B (0.60:1), C (0.00:1) and D (0.93:1) resulted in a ratio of $<1: 1$.

There was a much less pronounced effect of processing on the IVS zinc, although cooking of fermented flour (scenario D) caused a reduction, presumably due to the reactive hydroxyl groups and phytate, as was also discussed for iron. Although 
not significant, a positive trend in the IVS $\mathrm{Zn}$ can be observed from fermentation and cooking in kanwa, where it should be noted that the fermented product itself is not edible without cooking, the latter operation nullifying the improvement obtained from fermentation. Regarding the molar ratio of phytate to zinc, all products A (8.44:1), B (8.21:1), C (0.00:1) and $\mathrm{D}(8.42: 1)$ resulted in a ratio of $<10: 1$.

Regarding phytate, cooking had no diminishing effect, except when endogenous grain phytases were active (porridge C, see also Fig. 2, trace III). Fermentation decreased phytate levels, but cooking abrogated that effect, presumably by reversible reactions. Cooking in kanwa gave a slight reduction in the level of phytates, possibly because phytates will form complexes during cooking with the minerals present in the product and kanwa.

Cooking clearly has a significant effect on the level of polyphenolics since these form complexes with several food components during cooking. This effect is reflected in the decrease in reactive hydroxyl groups during cooking with kanwa, with more minerals being present in the porridge to form complexes with polyphenolics. In product $\mathrm{C}$, soaking had a significant effect on the level of polyphenolics. However, when cooking was applied next, the final porridge had the same phenolics levels as the untreated grain. Fermentation of wholemeal resulted in a significant increase in the level of reactive hydroxyl groups, but this was strongly reduced again after cooking.

\section{CONCLUSION}

Considering levels of IVS iron and zinc, the best results for iron were obtained with porridges $\mathrm{A}$ and $\mathrm{B}$. This was largely due to the milling method. Regarding the levels of reactive hydroxyl groups and phytate, porridge $\mathrm{C}$ is preferred. In order to produce porridges rich in IVS iron and zinc and low in phytate and hydroxyl groups, porridge $\mathrm{C}$ could be prepared by grinding the soaked grains in a cast steel mill, either in combination with a high mineral diet component or not. Kanwa might be used for that purpose. It should be noted, however, that the use of kanwa may darken the colour and affect the flavour of the porridge and thus may affect acceptability in consumer groups where kanwa is not known.

Porridge $\mathrm{C}$ is also interesting from other points of view. First, although its method of preparation seems similar to that for ben-saalga, it differs in that the slurry of milled soaked grains was not filtered. The presence of embryo and testa particles and their endogenous phytase activity during warming up prior to cooking of the porridge may have contributed to fully degrading the phytates. This may be a reason why porridge $\mathrm{C}$ had significantly lower levels of phytates than commercial ben-saalga (data not shown). A second point of interest is the effect of low $\mathrm{pH}$ in relation to the effectiveness of endogenous phytase enzyme activity. Whereas fermentation and acidification treatments $(\mathrm{pH} 3.8-4.0)$ both result in incomplete phytate degradation, soaked grains - with $\mathrm{pH}$ values ranging from 5.0 to 5.5 -allow full degradation. We postulate that a pronounced $\mathrm{pH}$ decrease ( $\mathrm{pH} 4$ or lower) has an inhibitory effect on endogenous phytase, similar to that observed in wheat sourdough. ${ }^{24}$ Although fermentation is desirable for its attractive organoleptic properties, the inactivation of phytate would be achieved better by first soaking whole grains, followed by grinding and fermentation. After fermentation, filtration could be carried out and porridge could be prepared from the filtrate, as is locally preferred for reasons of texture and colour.

\section{ACKNOWLEDGEMENTS}

The collaboration of Dr Dick Vreugdenhil and Diaan Jamar, Botanical Centre, Wageningen University, is gratefully acknowledged. This research was funded by the European Commission (CEREFER project, contract No. ICA4-CT-2002-10047).

\section{REFERENCES}

1 Hulse JH, Laing EM and Pearson OE, Sorghum and the Millets: Their Composition and Nutritive Value. Academic Press, London (1980).

2 FAO, Sorghum and Millets in Human Nutrition, Vol 27. FAO, Rome (1995).

3 Shahidi F and Naczk M, Phenolics in Food and Nutraceuticals. CRC Press, Boca Raton, FL (2004).

4 Bhat TK, Singh B and Sharma OP, Microbial degradation of tannins. Biodegradation 9:343-357 (1998).

5 Wales J and Sanger L, Tannin, in Wikipedia Encyclopedia. [Online]. Available: http://en.wikipedia.org/wiki/Tannin. Wikimedia Foundation, St Petersburg, FL [13 October 2005].

6 Hurrell RF, Lynch S, Bothwell T, Cori H, Glahn R, Hertrampf E, et al, Enhancing the absorption of fortification iron - a SUSTAIN Task Force report. Int $\mathcal{F}$ Vitam Nutr Res 74:387-401 (2004).

7 Towo EE, Svanberg U and Ndossi GD, Effect of grain pretreatment on different extractable phenolic groups in cereals and legumes commonly consumed in Tanzania. $\mathcal{f}$ Sci Food Agric 83:980-986 (2003).

8 Lestienne I, Icard-Vernière C, Mouquet $\mathrm{C}$, Picq $\mathrm{C}$ and Trèche $S$, Effects of soaking whole cereal and legume seeds on iron, zinc and phytate contents. Food Chem 89:421-425 (2005).

9 Lestienne I, Mouquet-Rivier C, Icard-Vernière C, Rochette I and Trèche $S$, The effects of soaking of whole, dehulled and ground millet and soybean seeds on phytate degradation and $\mathrm{Phy} / \mathrm{Fe}$ and Phy/Zn molar ratios. Int F Food Sci Technol 40:391-399 (2005).

10 Lestienne I, Contribution à l'étude de la biodisponibilité du fer et du zinc dans le grain de mil et conditions d'amélioration dans les aliments de complément. PhD thesis, Université Montpellier II Sciences et Techniques du Languedoc, Montpellier (2004).

11 Nout MJR, Ecology of accelerated natural lactic fermentation of sorghum-based infant food formulas. Int $\mathcal{F}$ Food Microbiol 12:217-224 (1991).

12 Kiers JL, Nout MJR and Rombouts FM, In vitro digestibility of processed and fermented soya bean, cowpea and maize. $\mathcal{F} \mathrm{Sci}$ Food Agric 80:1325-1331 (2000).

13 Temminghof E, Soil and Plant Analysis. Part 3. Plant Analysis Procedures. Wageningen University of Environmental Sciences, Wageningen (2000). 
14 Novozamsky I, van Eck R, Houba VJG and van der Lee JJ, Solubilisation of plant tissue with nitric acid-hydrofluoric acid-hydrogen peroxide in a closed system microwave digestor. Commun Soil Sci Plant Anal 27:867-875 (1996).

15 Bentsink L, Yuan K, Koornneef $M$ and Vreugdenhil D, The genetics of phytate and phosphate accumulation in seeds and leaves of Arabidopsis thaliana, using natural variation. Theor Appl Genet 106:1234-1243 (2003).

16 Dicko MH, Hilhorst R, Gruppen H, Traore A, Laane C, Van Berkel WJH, et al, Comparison of content in phenolic compounds, polyphenol oxidase and peroxidase in grains of fifty sorghum cultivars from Burkina Faso. $\mathcal{F}$ Agric Food Chem 50:3780-3788 (2002).

17 Hagerman AE, Tannin Chemistry. Miami University, Oxford, $\mathrm{OH}(2002)$.

18 Melake-Berhan A, Butler LG, Ejeta G and Menkir A, Grain mold resistance and polyphenol accumulation in sorghum. f Agric Food Chem 44:2428-2434 (1996).

19 Porter LJ, Hrstich LN and Chan BG, The conversion of procyanidins and prodelphinidins to cyanidin and delphinidin. Phytochemistry 25:223-230 (1986).
20 Price ML, Van Scoyoc S and Butler LG, A critical evaluation of the vanillin reaction as an assay for tannin in sorghum grain. f Agric Food Chem 26:1214-1218 (1978).

21 Matuschek E, Towo E and Svanberg U, Oxidation of polyphenols in phytate-reduced high-tannin cereals: effect on different phenolic groups and on in vitro accessible iron. $\mathcal{F}$ Agric Food Chem 49:5630-5638 (2001).

22 Sandberg A-S, Brune M, Carlsson N-G, Hallberg L, RossanderHulthen $L$ and Sandström B, The effect of various inositol phosphates on iron and zinc absorption in humans, in Bioavailability '93: Nutritional, Chemical and Food Processing Implications of Nutrient availability, ed. by Schlemmer U. Bundesforschungsanstalt für Ernährung, Karlsruhe, pp. 53-57 (1993).

23 Lo GS, Settle SL, Steinke FH and Hopkins DT, Effect of phytate:zinc molar ratio and isolated soybean protein on zinc bioavailablity. F Nutr 111:2223-2235 (1981).

24 Leenhardt F, Levrat Verny MA, Chanliaud E and Remesy C, Moderate decrease of $\mathrm{pH}$ by sourdough fermentation is sufficient to reduce phytate content of whole wheat flour through endogenous phytase activity. I Agric Food Chem 53:98-102 (2005). 